\title{
Mercury Content Transported from Atmosphere and Land to Jiaozhou Bay
}

\author{
Dongfang Yang ${ }^{1,2, a}$, Haixia $\mathrm{Li}^{1}$, Dongmei Jing ${ }^{1}$, Mingjing Tian ${ }^{1}$, Longlei Zhang ${ }^{1}$ \\ ${ }^{1}$ Accountancy School, Xijing University, Xi'an710123, China; \\ ${ }^{2}$ North China Sea Environmental Monitoring Center, SOA, Qingdao 266033, China;
}

\begin{abstract}
According to the data of May, August and October 1992, the range of Hg content in Jiaozhou Bay waters was $0.009-0.050 \mu \mathrm{g} / \mathrm{L}$, which met the water quality standard of class I sea water. This showed that in terms of $\mathrm{Hg}$ content, in May, August and October, the water of Jiaozhou Bay was clean and free from any $\mathrm{Hg}$ pollution. In May, the range of $\mathrm{Hg}$ content in Jiaozhou Bay waters was 0.009-0.038 $\mu \mathrm{g} / \mathrm{L}$. In August, the range of $\mathrm{Hg}$ content in Jiaozhou Bay waters was 0.021-0.050 $\mu \mathrm{g} / \mathrm{L}$. In October, the range of $\mathrm{Hg}$ content in Jiaozhou Bay waters was 0.011-0.040 $\mu \mathrm{g} / \mathrm{L}$. There were two sources of $\mathrm{Hg}$ content in Jiaozhou Bay waters, surface runoff and atmospheric deposition. The $\mathrm{Hg}$ content from surface runoffwas $0.038-0.040 \mu \mathrm{g} / \mathrm{L}$, and that from atmospheric deposition was $0.050 \mu \mathrm{g} / \mathrm{L}$. The model diagram was established to show the different paths and contents of $\mathrm{Hg}$ content in the process of input into Jiaozhou Bay. In May and October, the surface runoff was not polluted by any $\mathrm{Hg}$ content. In August, atmospheric deposition was not contaminated by any $\mathrm{Hg}$ content. That revealed that $\mathrm{Hg}$, humans issued to land and atmosphere, finally got to the ocean. There were two paths. One is that human beings discharge $\mathrm{Hg}$ into the atmosphere, and the $\mathrm{Hg}$ content reached into the ocean through atmospheric sedimentation. The $\mathrm{Hg}$ content from atmospheric sedimentation was relatively high, but the transportation time was relatively short. The other is that human beings discharge $\mathrm{Hg}$ content to the land. Through surface runoff, the $\mathrm{Hg}$ content reached into the ocean, and the $\mathrm{Hg}$ content from surface runoff was relatively low, but the transportation time was relatively short. With more and more paths, $\mathrm{Hg}$ content was decreasing.
\end{abstract}

\section{Introduction}

In modern times, with the development of industry, many industries released a lot of mercury $(\mathrm{Hg})$ to the environment in the process of production. In this way, human beings continuously discharge $\mathrm{Hg}$ content to land, atmosphere and ocean [1-14]. Therefore, the study on the pollution degree and source [1-14] of $\mathrm{Hg}$ content in offshore waters will help protect the marine environment and maintain ecological sustainable development. Based on the survey data in 1992, the content, horizontal distribution and source of $\mathrm{Hg}$ in Jiaozhou Bay water were analyzed. The water quality, source background and source quantity of Hg in Jiaozhou Bay water were studied for the study of the source, pollution degree and migration process of $\mathrm{Hg}$ in Jiaozhou Bay water.

\section{Investigation Waters and Methods}

\subsection{Natural Environments of Jiaozhou Bay}

Jiaozhou Bay is located in the south of Shandong Peninsula. Its geographical location is $120^{\circ} 04^{\prime}-120^{\circ}$ $23^{\prime} \mathrm{E}, 35^{\circ} 58^{\prime}-36^{\circ} 18^{\prime} \mathrm{N}$. It is bounded by the line between Tuan island and Xuejia island and connected with the Yellow Sea, covering an area of about $446 \mathrm{~km} 2$, with an average water depth of about $7 \mathrm{~m}$. It is a typical semi closed Bay. There are more than ten rivers flowing into the sea in Jiaozhou Bay, among which Dagu River, Yang River and Haibo River, Licun River and Loushan River are the ones with large runoff and sediment concentration. These are all seasonal rivers. The hydrological characteristics of these rivers can alter in different seasons $[15,16]$.

\subsection{Materials and Methods}

The survey data of Hg in Jiaozhou Bay in May, August and October 1992 were provided by the North Sea Monitoring Center of The State Oceanic Administration. 13 stations were set up in Jiaozhou Bay to take water samples: 52, 53, 54, 55, 56, 57, 58, 59, 60, 61, 2104, 2105 and 2106 stations (Figure 1). The samples were taken in May, August and October of 1992 respectively. According to the water depth, water samples were taken $(>10 \mathrm{~m}$, surface layer and bottom layer, and $<10 \mathrm{~m}$, only surface layer). The $\mathrm{Hg}$ content of Jiaozhou Bay water body was investigated according to the national standard

adfyang_dfyang@126.com 
method, which was included in the National Marine Monitoring Code (1991) [17].

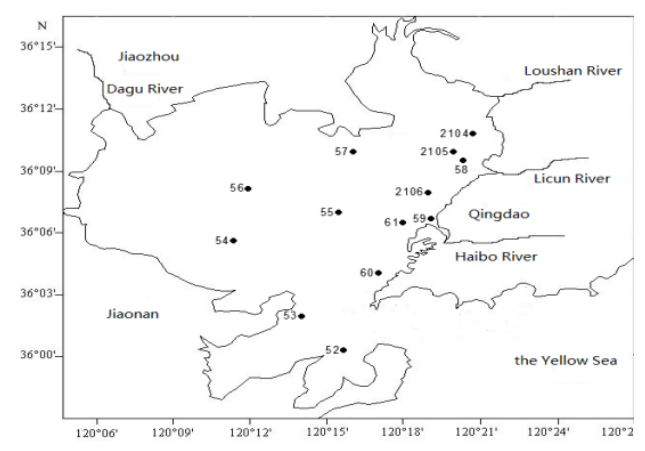

Fig.1 Investigation sites in Jiaozhou Bay

\section{Results}

\subsection{Content}

The quality standards for class I sea water $(0.05 \mu \mathrm{g} / \mathrm{L})$, class II sea water $(0.20 \mu \mathrm{g} / \mathrm{L})$ and class IV sea water $(0.50 \mu \mathrm{g} / \mathrm{L})$ were regulated by the administration. In May, August and October, the range of $\mathrm{Hg}$ content in Jiaozhou Bay waters were $0.009-0.050 \mu \mathrm{g} / \mathrm{L}$, which met the water quality standards of class I and class II seawater.

In May, the range of $\mathrm{Hg}$ content in Jiaozhou Bay waters was $0.009-0.038 \mu \mathrm{g} / \mathrm{L}$ (Table 1). The high value area was the coastal waters in the southwest of Jiaozhou Bay. In the coastal waters in the southwest of Jiaozhou Bay, the 54 station, the content of $\mathrm{Hg}$ in the water was $0.038 \mu \mathrm{g} / \mathrm{L}$, which meets the water quality standard of class I sea water $(0.05 \mu \mathrm{g} / \mathrm{L})$. In addition to the waters in the southwest of the Bay, other waters in Jiaozhou Bay, such as the waters in the northeast, North and center of the Bay, the $\mathrm{Hg}$ content is relatively low, less than $0.023 \mu \mathrm{g} / \mathrm{L}$. This shows that the water quality in the northeast, north and central waters of the bay is clean in terms of $\mathrm{Hg}$ content, which has reached the water quality standard of class I sea water.

In August, the range of $\mathrm{Hg}$ content in Jiaozhou Bay waters was $0.021-0.050 \mu \mathrm{g} / \mathrm{L}$ (Table 1 ). The high value area was the coastal waters in the east of Jiaozhou Bay. In the coastal waters in the east of Jiaozhou Bay, the 2106 station, the $\mathrm{Hg}$ content was higher than $0.050 \mu \mathrm{g} / \mathrm{L}$, which met the water quality standard of class I sea water $(0.05 \mu \mathrm{g} / \mathrm{L})$. In addition to the coastal waters in the east of the Bay, in other waters of Jiaozhou Bay, such as the waters in the northeast, north and center of the Bay, the content of $\mathrm{Hg}$ is relatively low, less than $0.037 \mu \mathrm{g} / \mathrm{L}$. It is in line with the national water quality standard of class I seawater $(0.05 \mu \mathrm{g} / \mathrm{L})$. In terms of $\mathrm{Hg}$ content, the waters was clean and met the water quality standard of class I seawater.

In October, the range of $\mathrm{Hg}$ content in Jiaozhou Bay waters was $0.011-0.040 \mu \mathrm{g} / \mathrm{L}$ (Table 1 ), and the high value areas appeared in the northwest, southwest, mouth and center of Jiaozhou Bay. In 56, 54, 53 and 55 Stations that were respectively in the northwest, southwest, mouth and center of Jiaozhou Bay, the content of $\mathrm{Hg}$ in the waters was higher than $0.040 \mu \mathrm{g} / \mathrm{L}$, which met the water quality standard of class I sea water $(0.05 \mu \mathrm{g} / \mathrm{L})$. Except the waters in the northwest, southwest, estuary and center of Jiaozhou Bay, the $\mathrm{Hg}$ content in other waters of Jiaozhou Bay, such as the waters in the northeast, north and east of Jiaozhou Bay, was relatively low, less than $0.029 \mu \mathrm{g} / \mathrm{L}$. This showed that the water quality in the northeast, north and east of the Bay, in terms of $\mathrm{Hg}$ content, was clean and met the water quality standard of class I sea water.

Therefore, in May, August and October, the range of $\mathrm{Hg}$ content in Jiaozhou Bay was 0.009-0.050 $\mu \mathrm{g} / \mathrm{L}$, which conformed to the water quality standard of class I sea water. This showed that in the aspect of $\mathrm{Hg}$ content, in May, August and October, the water quality of Jiaozhou Bay reached the water quality standard of class I seawater. The water quality is clean and free from any $\mathrm{Hg}$ pollution (Table 1).

Table 1 The quality of water surface in Jiaozhou bay in May, August and October

\begin{tabular}{|l|l|l|l|}
\hline & May & August & October \\
\hline $\begin{array}{l}\mathrm{Hg} \text { content in } \\
\text { seawater } / \mu \mathrm{g} \cdot \mathrm{L}-\end{array}$ & $0.009-$ & $0.021-$ & $0.011-$ \\
1 & & 0.050 & 0.040 \\
\hline $\begin{array}{l}\text { seawater } \\
\text { standard of } \\
\text { China }\end{array}$ & first-class & first-class & first-class \\
\hline
\end{tabular}

\subsection{Horizontal Distribution in Surface Layer}

In May, at 54 station in the coastal waters in the southwest of Jiaozhou Bay, the $\mathrm{Hg}$ content reached a high level of $0.038 \mu \mathrm{g} / \mathrm{L}$, and a series of parallel lines with different gradients were formed with the southwest waters as the center. The $\mathrm{Hg}$ content decreased from $0.038 \mu \mathrm{g} / \mathrm{L}$ in the center to $0.015 \mu \mathrm{g} / \mathrm{L}$ in the eastern part of the Bay and $0.009 \mu \mathrm{g} / \mathrm{L}$ in the northern part of the Bay (Fig. 2).

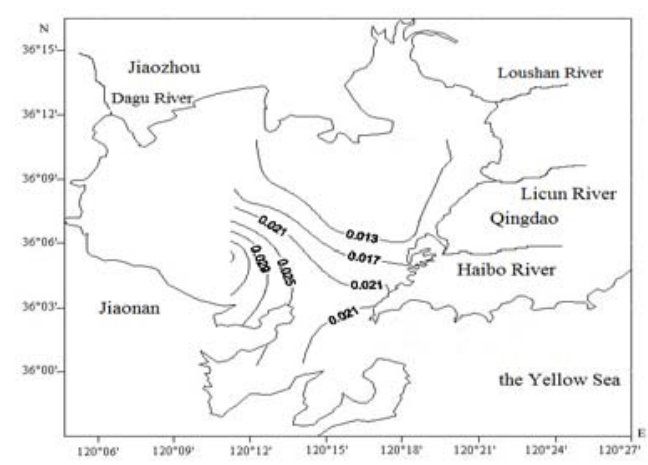

Fig.2 Hg content distribution at the surface in Jiaozhou Bay in $\operatorname{May}(\mu \mathrm{g} / \mathrm{L})$

In August, at the 2106 station in the eastern waters of Jiaozhou Bay, the $\mathrm{Hg}$ content reached a high level of $0.050 \mu \mathrm{g} / \mathrm{L}$, and a high $\mathrm{Hg}$ content area was formed with the eastern waters as the center, forming a series of semi concentric circles with different gradients. The Hg content decreased from $0.050 \mu \mathrm{g} / \mathrm{L}$ in the center to $0.021 \mu \mathrm{g} / \mathrm{L}$ in the center of the Bay (Fig. 3). 


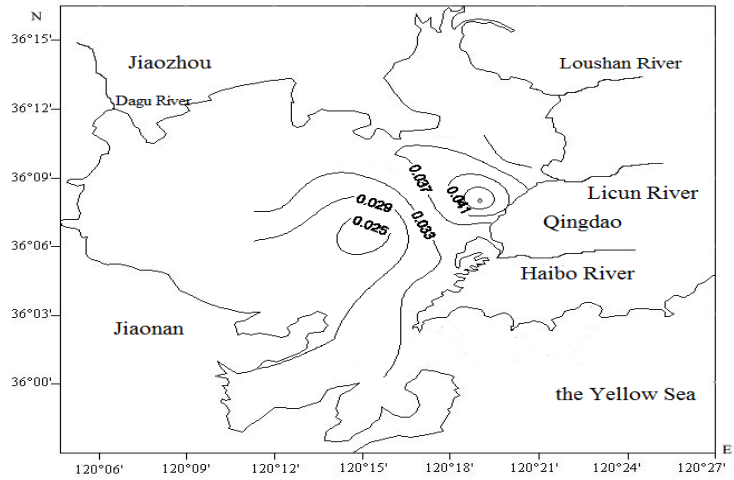

Fig.3 Hg content distribution at the surface in Jiaozhou Bay in $\operatorname{August}(\mu \mathrm{g} / \mathrm{L})$

In October, at the 56 station in the northwest of Jiaozhou Bay, 54 station in the southwest, 53 station at Wankou and 55 station in the center of Jiaozhou Bay, the $\mathrm{Hg}$ content reached $0.040 \mu \mathrm{g} / \mathrm{L}$, a high $\mathrm{Hg}$ content area was formed with the water area in the southwest of Jiaozhou Bay as the center, forming a series of parallel lines with different gradients. The $\mathrm{Hg}$ content decreased from $0.040 \mu \mathrm{g} / \mathrm{L}$ in the center to $0.011 \mu \mathrm{g} / \mathrm{L}$ in the north of the Bay, $0.015 \mu \mathrm{g} / \mathrm{L}$ in the east of the Bay and 0.011 $\mu \mathrm{g} / \mathrm{L}$ in the southeast of the Bay (Figure 4).

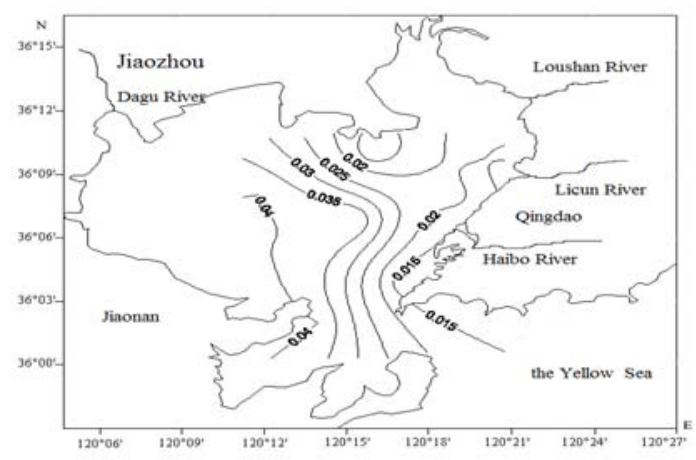

Fig. $4 \mathrm{Hg}$ content distribution at the surface in Jiaozhou Bay in October $(\mu \mathrm{g} / \mathrm{L})$

\section{Discussion}

\subsection{Water Quality}

In May, August and October, the range of $\mathrm{Hg}$ content in Jiaozhou Bay waters was 0.009-0.050 $\mu \mathrm{g} / \mathrm{L}$, which met the water quality standard of class I seawater. This showed that in terms of $\mathrm{Hg}$ content, in May, August and October, the water of Jiaozhou Bay was clean and free from any $\mathrm{Hg}$ pollution.

In May, the range of $\mathrm{Hg}$ content in Jiaozhou Bay water was $0.009-0.038 \mu \mathrm{g} / \mathrm{L}$, and the water area of Jiaozhou Bay was not polluted by $\mathrm{Hg}$. In the coastal waters in the southwest of Jiaozhou Bay, the $\mathrm{Hg}$ content reached a relatively high level of $0.038 \mu \mathrm{g} / \mathrm{L}$, which showed that the seawater quality has reached the water quality standard of a class of seawater, and the waters was not polluted by $\mathrm{Hg}$. Except the water area in the southwest of Jiaozhou Bay, the content of $\mathrm{Hg}$ was relatively low in other waters of
Jiaozhou Bay, which met the national water quality standard of class I sea water. The water was clean and not polluted by $\mathrm{Hg}$.

In August, the range of $\mathrm{Hg}$ content in Jiaozhou Bay waters was $0.021-0.050 \mu \mathrm{g} / \mathrm{L}$, and the water area of Jiaozhou Bay was not polluted by $\mathrm{Hg}$. In the coastal waters in the east of Jiaozhou Bay, the content of $\mathrm{Hg}$ has reached a relatively high level of $0.050 \mu \mathrm{g} / \mathrm{L}$, which showed that the water quality of seawater has reached the water quality standard of a class of seawater, and the waters was not been polluted by $\mathrm{Hg}$. Except the coastal waters in the east of Jiaozhou Bay, the content of $\mathrm{Hg}$ is relatively low in other waters of Jiaozhou Bay, which met the water quality standard of national class I seawater. The water was clean and has not been polluted by $\mathrm{Hg}$.

In October, the range of $\mathrm{Hg}$ content in Jiaozhou Bay waters was $0.011-0.040 \mu \mathrm{g} / \mathrm{L}$, and the water area of Jiaozhou Bay was not polluted by $\mathrm{Hg}$. In the waters of the northwest, southwest, mouth and center of Jiaozhou Bay, the $\mathrm{Hg}$ content has reached a relatively high level of 0.040 $\mu \mathrm{g} / \mathrm{L}$, which showed that the sea water quality has reached the water quality standard of class I sea water, and the water was not been polluted by Hg. Except the water areas in the northwest, southwest, Wankou and the center of the Bay, the $\mathrm{Hg}$ content was relatively low, which met the water quality standard of the national class I seawater. The water was clean and not polluted by $\mathrm{Hg}$.

\subsection{Source}

In May, a high $\mathrm{Hg}$ content area was formed in the southwest water area of Jiaozhou Bay, which indicated that the source of $\mathrm{Hg}$ was the surface runoff. The content of $\mathrm{Hg}$ in transportation was $0.038 \mu \mathrm{g} / \mathrm{L}$, which was relatively high.

In August, a high content area of $\mathrm{Hg}$ was formed in the eastern waters of Jiaozhou Bay, which indicated that the source of $\mathrm{Hg}$ was atmospheric deposition. The $\mathrm{Hg}$ content in transportation was $0.050 \mu \mathrm{g} / \mathrm{L}$, which was very high.

In October, a high content area of $\mathrm{Hg}$ was formed in the southwest water area of Jiaozhou Bay, which indicated that the source of $\mathrm{Hg}$ was surface runoff. The content of $\mathrm{Hg}$ in transportation was $0.040 \mu \mathrm{g} / \mathrm{L}$, which was relatively high.

Therefore, in May, the $\mathrm{Hg}$ content transported by surface runoff to Jiaozhou Bay was $0.038 \mu \mathrm{g} / \mathrm{L}$, which was in line with the national class I sea water quality standard of $0.05 \mu \mathrm{g} / \mathrm{L}$. This indicated that the surface runoff was not contaminated by any $\mathrm{Hg}$ content (Table 2). In August, the $\mathrm{Hg}$ content transported to Jiaozhou Bay from atmospheric subsidence was $0.050 \mu \mathrm{g} / \mathrm{L}$, which was in line with the national class I sea water quality standard of $0.05 \mu \mathrm{g} / \mathrm{L}$. This indicated that the atmospheric deposition was not contaminated by any $\mathrm{Hg}$ content (Table2). In October, the content of $\mathrm{Hg}$ transported by surface runoff to Jiaozhou Bay was $0.040 \mu \mathrm{g} / \mathrm{L}$, which was in line with the national class I sea water quality standard of $0.05 \mu \mathrm{g} / \mathrm{L}$. This indicated that the surface runoff was not contaminated by any $\mathrm{Hg}$ content (Table2). 
Table.2 The Hg contents from the different sources in Jiaozhou bay

\begin{tabular}{|c|c|c|c|}
\hline Time & May & August & October \\
\hline Sources & $\begin{array}{c}\text { Surface } \\
\text { runoff }\end{array}$ & $\begin{array}{c}\text { atmospheric } \\
\text { deposition }\end{array}$ & $\begin{array}{c}\text { Surface } \\
\text { runoff }\end{array}$ \\
\hline $\begin{array}{c}\mathrm{Hg} \\
\text { content } / \mathrm{\mu g} \cdot \mathrm{L} 1\end{array}$ & 0.038 & 0.050 & 0.040 \\
\hline
\end{tabular}

\subsection{Model Diagram of Transportation}

There are two sources of $\mathrm{Hg}$ content in Jiaozhou Bay waters, surface runoff and atmospheric deposition. The $\mathrm{Hg}$ content from surface runoff was between 0.038-0.040 $\mu \mathrm{g} / \mathrm{L}$, and that from atmospheric deposition was 0.050 $\mu \mathrm{g} / \mathrm{L}$. The model diagram was established to show the different paths and contents of $\mathrm{Hg}$ content in the process of entering Jiaozhou Bay (Fig. 5). In this way, the migration process of $\mathrm{Hg}$ content from human emission to atmosphere and ocean was quantitatively revealed.

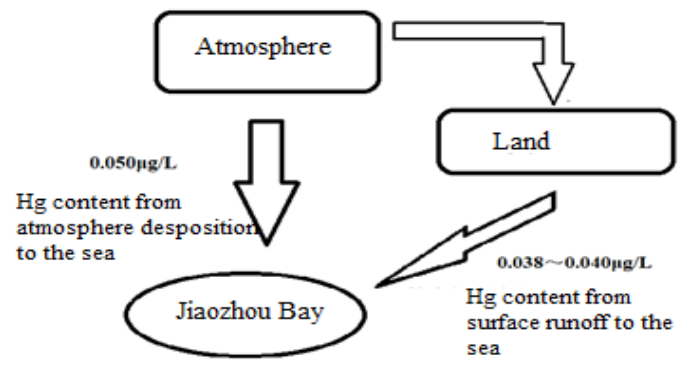

Fig.5 the main source of the $\mathrm{Hg}$ content into the Jiaozhou bay $(\mu \mathrm{g} / \mathrm{L})$

In May, the $\mathrm{Hg}$ content in transportation from surface runoff to Jiaozhou Bay was $0.038 \mu \mathrm{g} / \mathrm{L}$, a relatively low level. This showed that the surface runoff was not polluted by any $\mathrm{Hg}$ content.

In August, the $\mathrm{Hg}$ content in transportation from atmospheric deposition to Jiaozhou Bay was $0.050 \mu \mathrm{g} / \mathrm{L}$ $\mathrm{Hg}$, a relatively high level. And the atmospheric deposition was not polluted by any $\mathrm{Hg}$ content.

In October, the $\mathrm{Hg}$ content in transportation from surface runoff to Jiaozhou Bay was $0.040 \mu \mathrm{g} / \mathrm{L}$, a relatively low level. And the surface runoff was not polluted by any $\mathrm{Hg}$ content.

\subsection{Change of Content in Transportation}

In May, the $\mathrm{Hg}$ content transported from surface runoff to Jiaozhou Bay was $0.038 \mu \mathrm{g} / \mathrm{L}$, and the surface runoff was not polluted by any $\mathrm{Hg}$ content. This showed that the $\mathrm{Hg}$ content of human emissions to land was relatively low, and the $\mathrm{Hg}$ content of direct emissions to the ocean through surface runoff was also relatively low. In this way, there is no pollution of $\mathrm{Hg}$ content on land.

In August, the $\mathrm{Hg}$ content transported to Jiaozhou Bay by atmospheric deposition was $0.050 \mu \mathrm{g} / \mathrm{L}$, and the atmospheric deposition was not polluted by any $\mathrm{Hg}$ content, which revealed that the Hg content of human emissions to the atmosphere was relatively high, which brought about the increase of the migration paths of the $\mathrm{Hg}$ content, so that the area of human emissions through the atmosphere was expanding. On the other hand, after a long time of human input to the ocean, the $\mathrm{Hg}$ content of the ocean has increased, and the ocean was polluted lightly.

In October, the $\mathrm{Hg}$ content transported from the surface runoff to Jiaozhou Bay was $0.040 \mu \mathrm{g} / \mathrm{L}$, and the surface runoff was not polluted by any $\mathrm{Hg}$ content. This showed that from May to October, human issued $\mathrm{Hg}$ content to land continuously, and the $\mathrm{Hg}$ content of human emission to land is relatively low. However, the duration of emission was relatively long, and the $\mathrm{Hg}$ content of human emission to land was relatively stable: $0.038-0.040$ $\mu \mathrm{g} / \mathrm{L}$. The content of $\mathrm{Hg}$ discharged directly to the ocean through surface runoff was also relatively low. In this way, there is no pollution of $\mathrm{Hg}$ content on land.

That revealed that $\mathrm{Hg}$ content, humans issued to land and atmosphere, finally got to the ocean. There were two paths. One is that human beings discharge $\mathrm{Hg}$ into the atmosphere, and the $\mathrm{Hg}$ content reached into the ocean through atmospheric sedimentation. The $\mathrm{Hg}$ content from atmospheric sedimentation was relatively high, but the transportation time was relatively short. The other is that human beings discharge $\mathrm{Hg}$ content to the land. Through surface runoff, the $\mathrm{Hg}$ content reached into the ocean, and the $\mathrm{Hg}$ content from surface runoff was relatively low, but the transportation time was relatively short. With more and more paths, $\mathrm{Hg}$ content was decreasing.

\section{Conclusion}

In May, August and October, the range of $\mathrm{Hg}$ content in Jiaozhou Bay waters was $0.009-0.050 \mu \mathrm{g} / \mathrm{L}$, which met the water quality standard of class I seawater. This showed that in terms of $\mathrm{Hg}$ content, in May, August and October, the water of Jiaozhou Bay was clean and free from any $\mathrm{Hg}$ pollution.

In May, the range of $\mathrm{Hg}$ content in Jiaozhou Bay water was $0.009-0.038 \mu \mathrm{g} / \mathrm{L}$, and the water area of Jiaozhou Bay was not polluted by $\mathrm{Hg}$. In the coastal waters in the southwest of Jiaozhou Bay, the content of $\mathrm{Hg}$ reached a relatively high level of $0.038 \mu \mathrm{g} / \mathrm{L}$. In other waters of Jiaozhou Bay, the content of $\mathrm{Hg}$ was relatively low.

In August, the range of $\mathrm{Hg}$ content in Jiaozhou Bay water was $0.021-0.050 \mu \mathrm{g} / \mathrm{L}$, and the water area of Jiaozhou Bay was not polluted by $\mathrm{Hg}$. In the coastal waters in the east of Jiaozhou Bay, the content of $\mathrm{Hg}$ was $0.050 \mu \mathrm{g} / \mathrm{L}$, a relatively high level, and in other waters of Jiaozhou Bay, the content of $\mathrm{Hg}$ was relatively low.

In October, the range of $\mathrm{Hg}$ content in Jiaozhou Bay water was $0.011-0.040 \mu \mathrm{g} / \mathrm{L}$, and the water area of Jiaozhou Bay was not polluted by Hg. In the northwest, southwest, mouth and center of Jiaozhou Bay, the content of $\mathrm{Hg}$ was $0.040 \mu \mathrm{g} / \mathrm{L}$, higher than that in other waters.

There are two sources of $\mathrm{Hg}$ content in Jiaozhou Bay waters, surface runoff and atmospheric deposition. The $\mathrm{Hg}$ content from surface runoff was $0.038-0.040 \mu \mathrm{g} / \mathrm{L}$, and that from atmospheric deposition was $0.050 \mu \mathrm{g} / \mathrm{L}$. The model diagram was established to show the different paths and contents of $\mathrm{Hg}$ content in the process of input 
into Jiaozhou Bay. This quantitatively revealed the migration process of $\mathrm{Hg}$ content from human emissions to the atmosphere and land.

Therefore, in May and October, the surface runoff was not polluted by any $\mathrm{Hg}$ content. In August, atmospheric deposition was not contaminated by any $\mathrm{Hg}$ content.

$\mathrm{Hg}$ content that humans issued to land and atmosphere, finally got to the ocean. There were two paths. One is that human beings discharge $\mathrm{Hg}$ into the atmosphere, and the $\mathrm{Hg}$ content reached into the ocean through atmospheric sedimentation. The $\mathrm{Hg}$ content from atmospheric sedimentation was relatively high, but the transportation time was relatively short. The other is that human beings discharge $\mathrm{Hg}$ content to the land. Through surface runoff, the $\mathrm{Hg}$ content reached into the ocean, and the $\mathrm{Hg}$ content from surface runoff was relatively low, but the transportation time was relatively short. With more and more paths, $\mathrm{Hg}$ content was decreasing.

\section{References}

1. Dongfang Yang, Zhenhui Gao. Marine Bay Ecology [M]. Beijing: CHINA CULTURE PUBLISHING HOUSE. 2006.

2. Dongfang Yang, Zhenqing Miao. Marine Bay Ecology (Volume 1) [M]. Beijing: China Ocean Press, 2010, 1-320.

3. Dongfang Yang, Zhenhui Gao. Marine Bay Ecology (Volume 2) [M]. Beijing: China Ocean Press, 2010, 1-330.

4. Chen Yu, Gao Zhenhui, Qu Yanheng, Yang Dongfang and Tang Hongxia. Mercury distribution in the Jiaozhou Bay[J]. Chin. J. Oceanol. Limnol. 2007, 25(4): 455-458.

5. Dongfang Yang, Hairong Cao, Zhenhui Gao, Qing Lu, Yanfeng Qu. Hg in Jiaozhou Bay I.Distribution and transition [J].Marine Environmental Science, 2008, 27 (1): 37-39.

6. Dongfang Yang, Leilei Wang, Zhenhui Gao, Lian Ju, Jiping Zeng. Hg in Jiaozhou Bay II. Distribution and pollution sources [J]. Marine Environmental Science, 2009, 28 (5): 501-505.

7. Yu Chen, Yinjiang Zhang, Junhui Guo, Qiang Shi, Dongfang Yang. Distribution and Seasonal Variation of $\mathrm{Hg}$ (Heavy Metal) in the Waterbody of Jiaozhou Bay [J]. Ocean Development and Management, 2013, 30(6):81-83.

8. Dongfang Yang, Peiyan Sun, Chen Chen, Hongyan Bai, Qing Zhou. Pollution Source and Distribution of PHC in the Jiaozhou Bay Waters [J]. Coastal Engineering, 2013, 32(1): 60-72.

9. Dongfang Yang, Zijun Xu, Yanfeng Qu, Yanrong Zhou, Fei Teng. Distribution and Input Way of $\mathrm{Hg}$ in the Jiaozhou Bay [J]. Coastal Engineering, 2014, 33 (1): 67-78.

10. Yu Chen, Yanfeng Qu, Renlin Pei and Dongfang Yang. Effect of $\mathrm{Hg}$ in Jiaozhou Bay waters- The aquatic transfer process[J]. Advanced Materials Research Vols.955-959. 2014, 2491-2495.
11. Dongfang Yang, Sixi Zhu, Fengyou Wang, XiuqinYang and Yunjie Wu. Effect of Hg in Jiaozhou Bay waters- The land transfer process[J]. Advanced Materials Research Vols.955-959. 2014, 2496-2500.

12. Dongfang Yang, Sixi. Zhu, Fengyou Wang, Huazhoung $\mathrm{He}$ and Yunjie $\mathrm{Wu}$. Effect of $\mathrm{Hg}$ in Jiaozhou Bay waters- The Temporal variation of the $\mathrm{Hg}$ content $[\mathrm{J}]$. Applied Mechanics and Materials Vols.556-562. 2014, 633-636.

13. Dongfang Yang, Fengyou Wang, Huazhong He, Youfu $\mathrm{Wu}$ and Sixi Zhu. Effect of $\mathrm{Hg}$ in Jiaozhou Bay waters- The change process of the $\mathrm{Hg}$ pollution sources[J]. Advanced Materials Research Vols.955959. 2014, 1443-1447.

14. Dongfang Yang, Xiao Geng, Yanfeng Qu, Hongyan Bai, Zijun Xu. Distribution and Gravity Characteristics of $\mathrm{Hg}$ (Heavy Metal) in the Waterbody of Jiaozhou Bay [J].Ocean Development and Management, 2014, 31 (12): 71-77.

15. YANG D F, CHEN Y, GAO Z H, et al. Silicon Limitation on primary production and its destiny in Jiaozhou Bay, China IV transect offshore the coast with estuaries [J]. Chin. J. Oceanol. Limnol. 2005, 23(1): 72-90.

16. Dongfang Yang, Fan Wang, Zhenhui Gao, et al. Ecological Phenomena of Phytoplankton in Jiaozhou Bay [J]. Marine Science, 2004, 28 (6): 71-74.

17. State Oceanic Administration. The Specification for Marine Monitoring [Z]. Beijing: China Ocean Press, 1991. 